\title{
Correlation Between Fine Needle Aspiration Cytology (FNAC) and Permanent Histopathology Results in Salivary Gland Masses
}

Ghassan Z. AlGhamdi ${ }^{1}$, Ali K. Alzahrani ${ }^{2}$, Hisham Saati ${ }^{1}$, Hussam M. Algarni ${ }^{3}$, Khalid A. Alshehri ${ }^{1}$, Muhannad Baroom ${ }^{4}$, Baraa I. Awad ${ }^{5}$, Mohammed Algarni ${ }^{4}$, Hadi Afandi Al-Hakami ${ }^{5}$

1. Medicine, College of Medicine, King Saud Bin Abdulaziz University for Health Sciences, Jeddah, SAU 2. Otolaryngology - Head and Neck Surgery, King Saud Bin Abdulaziz University for Health Sciences, Jeddah, SAU 3. Orthopaedics, King Saud Bin Abdulaziz University for Health Sciences, Jeddah, SAU 4. Otolaryngology - Head and Neck Surgery, College of Medicine, King Saud Bin Abdulaziz University for Health Sciences, Jeddah, SAU 5. College of Medicine, Department of Otolaryngology - Head \& Neck Surgery, King Saud bin Abdulaziz University for Health Sciences, King Abdullah International Medical Research Center, Ministry of National Guard Health Affairs, Jeddah, SAU

Corresponding author: Ali K. Alzahrani, ali_khaled1996@hotmail.com

\section{Abstract}

\section{Objective}

Fine-needle aspiration cytology (FNAC) has been widely accepted as a diagnostic safe method for preoperative assessment of salivary gland lesions. This diagnostic tool is inexpensive, easy to perform, relatively painless and it provides useful information to differentiate between benign and malignant salivary gland tumors that helps in the management and surgical planning. This study was undertaken to compare FNAC results with permanent histopathological findings of salivary gland tumors in order to assess its diagnostic accuracy.

\section{Materials and methods}

A total of 37 archived salivary gland FNAC specimens collected between January 2001 and January 2018 were correlated with proven histopathology findings. Sensitivity, specificity, positive and negative predictive values, and diagnostic accuracy were calculated. False negative and false positive cases were determined.

\section{Results}

There were 20 female and 17 male patients. Parotid tumors count for $62.2 \%$ and submandibular tumors $37.8 \%$. All cases of malignancy on FNAC were proven to be malignant on the final pathology findings. All cases that were suspicious for malignancy on FNAC were proven to be malignant as well. In addition, three false negative cases were seen and no false positive cases among all FNAC cases. In our series, the overall sensitivity and specificity were $90.3 \%$ and $100 \%$, respectively. The positive and negative predictive values were $100 \%$ and $57.1 \%$, respectively. The diagnostic accuracy was $91.4 \%$.

Review began 03/13/2021 Review ended 03/16/2021 Published 03/18/2021

\section{๑) Copyright 2021}

AlGhamdi et al. This is an open access article distributed under the terms of the Creative Commons Attribution License CC-BY 4.0 , which permits unrestricted use, distribution, and reproduction in any medium, provided the original author and source are credited.

\section{Conclusion}

This study demonstrated that FNA cytology of the salivary gland is a useful technique for diagnosis of salivary gland lesions. Insufficient cellularity was the most important factor that resulted in incorrect cytological interpretation.

Categories: Otolaryngology, Pathology, Oncology

Keywords: salivary gland mass, fine needle aspiration, cytology, cytopathology

\section{Introduction}

Salivary gland tumors include a variety of different morphological and pathological groups of neoplasms that are not common and the associated histopathology is extremely varied and complex. These varieties of salivary gland lesions include epithelial neoplasms, non-epithelial lesions, lymphomas, metastatic tumors and non-neoplastic lesions. This variation further contributes to the diagnostic difficulty [1]. In the United States, new cases are estimated to be nearly $2.5-3.0$ cases per 100,000 per year [2]. Malignant salivary gland neoplasms account approximately $3-5 \%$ of all head and neck tumors and more than $0.5 \%$ of all malignancies [2]. Fine-needle aspiration cytology (FNAC) is used widely in the preoperative assessment of head and neck tumors including salivary gland tumors. This diagnostic procedure is a safe, quick, simple, inexpensive, well-accepted and well-tolerated by patients. Although head and neck lesions are more easily accessible by FNA, diagnosis of salivary gland lesions by FNA is a controversial issue [3-5]. This method can help to differentiate between benign and malignant salivary gland tumors. It was found that FNAC in comparison to histological findings of parotid gland lesions in particular had a concordance rate of $86 \%$, a specificity of $98 \%$, a sensitivity of $86 \%$, and a diagnostic accuracy of $94 \%$ [1]. Despite these findings, there are still 
concerns about its use as a main method of diagnosis due to its relatively low sensitivity in malignancy cases and its variation in results [6].

In addition to the insufficient cellularity, there are several confounding cytologic factors that make some FNA specimens difficult to interpret. Furthermore, some salivary gland malignancies can only be diagnosed by the presence of capsular invasion, which is not assessable by FNA [7]. Up to our knowledge, there is no study in Saudi Arabia addressing the correlation between fine needle aspiration cytology and histopathological results of salivary gland lesions. The aim of this retrospective study is to correlate FNAC results with the final histopathological findings of salivary gland tumors and to determine the diagnostic yield of FNA cytology and its accuracy.

\section{Materials And Methods Patients and specimens}

This is a retrospective study consisting of 37 FNA specimens of salivary glands obtained from the archives of the cytology laboratory and the health information system "BESTCare", which were verified by histopathological diagnosis. Those patients had presented to ENT-Head and Neck clinics and had a parotidectomy or submandibular gland surgery at the King Abdul Aziz Medical City, Jeddah in a span of 17 years from January 2001 to January 2018. The study was approved by King Abdullah International Medical Research Center and IRB ethical approval was given with ID: SP20/123/J. Specimens with lack of pathologic confirmation or unsatisfactory cytology, such as blood only or no cells, were excluded. In addition, specimens not treated by surgery were also excluded. The FNA cytologic results were classified into four diagnostic categories: benign tumor, benign lesion, suspicion of malignancy, and malignant. Benign lesions refer to atypical cells that cannot be differentiated between reactive or neoplastic activity. The pathology of surgical specimens was classified into two main diagnostic categories: benign and malignant. For each individual patient we compared the histopathology of the permanent surgical specimens with the preoperative cytology of the FNAC samples.

\section{Statistical analysis}

For data analysis we used SPSS Base version 20.0. (IBM Corp., Armonk, NY). The sensitivity, specificity, positive predictive value (PPV), negative predictive value (NPV), and overall accuracy of FNAC were calculated using standard statistical methods to differentiate between benign and malignant disease. The qualitative variables presented as frequencies and percentages and the quantitative variables as mean and standard deviation. In order to compare the qualitative variables, we used the chi-square test. For comparing the quantitative variables, the t-test was used.

\section{Results}

Among 37 specimens verified by pathology, there were 20 female and 17 male patients. The female-to-male ratio was approximately 1 to 1.2 . The age range was 13 months to 93 years with a mean age of 56 years. Parotid tumors were $62.2 \%$ and submandibular tumors were $37.8 \%$. Table 1 shows the general description of the salivary gland lesions. FNA cytologic diagnoses showed malignancy in 28 cases (75.7\%), suspicion of malignancy in two (5.4\%) and benign tumors and lesions in seven (18.9\%). Table 2 shows the details of FNA cytology results in each category. The final pathologic diagnoses showed 33 malignant tumors $(89.2 \%)$ and four (10.8\%) benign tumors. Table 3 demonstrates the final histopathological results of each category. The most common benign tumor in both FNAC and final histopathology was pleomorphic adenoma. The most common malignancies in both were mucoepidermoid and adenoid cystic carcinoma. The correlation between FNAC and final pathologic results is demonstrated in Table 4. Three cases were false negative on FNAC, one case of pleomorphic adenoma and the other two were benign lesions. All cases of malignancy on FNAC were proven to be malignant on the final pathology. All cases that were suspicious for malignancy on FNAC were proven to be malignant as well. No false positive cases were seen among all FNAC cases. In our series, the overall sensitivity and specificity were $90.3 \%$ and $100 \%$, respectively. The positive and negative predictive values were $100 \%$ and $57.1 \%$, respectively. For determining the diagnostic accuracy of FNAC, the results of FNAC of each case were compared with the final histopathological diagnosis, as illustrated in Table 4. The diagnostic accuracy was $91.4 \%$. 


\section{Cureus}

Variables

No. (\%)

Gender

Male

$17(45.9)$

Female

$20(54.1)$

Median age

56 years

Site

Parotid gland

$23(62.2)$

Submandibular gland

$14(37.8)$

TABLE 1: General description of patients with salivary gland masses

\begin{tabular}{|c|c|}
\hline Category & No. (\%) \\
\hline \multicolumn{2}{|l|}{ Benign tumors } \\
\hline Pleomorphic adenoma & 5 (13.5) \\
\hline Benign lesions & $2(5.4)$ \\
\hline Suspicious for malignancy & $2(5.4)$ \\
\hline Malignancy & $28(75.7)$ \\
\hline Mucoepidermoid carcinoma & $10(27.0)$ \\
\hline Adenoid cystic carcinoma & 7 (18.9) \\
\hline Acinic cell carcinoma & $2(5.4)$ \\
\hline Squamous cell carcinoma & $2(5.4)$ \\
\hline Undifferentiated carcinoma & $2(5.4)$ \\
\hline Poorly differentiated carcinoma & $1(2.7)$ \\
\hline Epithelial-myoepithelial carcinoma & $1(2.7)$ \\
\hline Hemangiopericytoma & $1(2.7)$ \\
\hline Neuroblastoma & $1(2.7)$ \\
\hline Rhabdomyosarcoma & $1(2.7)$ \\
\hline
\end{tabular}

\section{TABLE 2: Categorization of FNAC results}

FNAC: Fine needle aspiration cytology 


\section{Cureus}

Category

No. (\%)

Benign tumors

Pleomorphic adenoma

4 (10.8)

Malignancy

33 (89.2)

Mucoepidermoid carcinoma

$11(29.7)$

Adenoid cystic carcinoma

9 (24.3)

Acinic cell carcinoma

Squamous cell carcinoma

Undifferentiated carcinoma

poorly differentiated carcinoma

Epithelial-myoepithelial carcinoma

Lymphoepithelial carcinoma

Hemangiopericytoma

Neuroblastoma

Rhabdomyosarcoma

TABLE 3: Categorization of final histopathological specimens

\begin{tabular}{|c|c|c|c|c|c|}
\hline \multirow{2}{*}{ Total } & \multicolumn{4}{|l|}{ Cytology } & \multirow{2}{*}{ Histopathology } \\
\hline & Malignant tumors & Suspicious for malignancy & Benign lesions & Benign tumors & \\
\hline 4 & 0 & 0 & 0 & 4 & Benign tumors \\
\hline 33 & 28 & 2 & 2 & 1 & Malignant tumors \\
\hline \multicolumn{6}{|c|}{$\begin{array}{l}\text { TABLE 4: Correlation of FNA cytologic and final histopathologic diagnosis of } 37 \text { salivary gland } \\
\text { lesions }\end{array}$} \\
\hline \multicolumn{6}{|c|}{ FNA: Fine needle aspiration } \\
\hline
\end{tabular}

\section{Discussion}

For the diagnosis of salivary gland neoplasms, fine needle aspiration is a safe and cost-effective method. FNAC can be done in an outpatient setting with low risk of complications [8]. The main goal of FNA is to determine if a mass is inflammatory and/or reactive, benign or malignant neoplasm and if possible, to render a specific diagnosis. The preoperative information concerning the tumor type can be informative to plan the best surgical approach. Close cooperation between the clinician and an experienced cytopathologist provides good outcome in FNA procedures. FNA in salivary gland lesions is one of the most difficult areas in cytopathology due to the overlapping morphologic patterns in many benign and malignant salivary gland neoplasms. Furthermore, histological patterns may show various differences within the same tumor $[9,10]$. Even though it has commonly become one of the initial tests to evaluate parotid masses, there is still some controversy regarding its effectiveness due to its low sensitivity in differentiating benign from malignant tumors [6].

In our study, we observed that most of the cases were malignant which could be explained by the referral system of our oncology center. Three cases were false negative on FNAC, one case of pleomorphic adenoma and other two were benign lesions. All cases of malignancy on FNAC were proven to be malignant on the final pathology. All cases that were suspicious for malignancy on FNAC were proven to be malignant as well. No false positive cases were seen among all FNAC cases. In our series, the overall sensitivity and specificity were $90.3 \%$ and $100 \%$, respectively. The positive and negative predictive values were $100 \%$ and 
$57.1 \%$, respectively. The diagnostic accuracy was $91.4 \%$.

Our results are comparable with the other literature regarding the effectiveness of FNAC in the evaluation of salivary gland masses. A review of the literature showed an FNAC sensitivity ranging from $54 \%$ to $92 \%$ and a specificity of $86-100 \%$ [8].

In one study where they reviewed 129 patients who underwent parotidectomy, similar results were shown with FNAC having a sensitivity of $84 \%$ and a specificity of $94 \%$. The overall accuracy of FNAC in their study was around 94\% [1]. Another study which was a retrospective chart review of 114 patients showed that FNAC had a sensitivity of $73 \%$ and a specificity of $97 \%$. The overall accuracy of FNAC in that study was $95 \%$ [8]. Furthermore, the accuracy of FNAC in recent literature has ranged from $84 \%$ to $97 \%$ in comparison with our study which was $91.4 \%$ [11-13].

To answer our research question in regard to the accuracy of FNAC in correlation with histopathologic findings, it is fair to say that FNAC has high specificity that can help the surgeon in the counseling and management of the patients. Fine needle aspiration cytology of salivary gland lesions in particular needs expert cytopathologists and a collaborative team discussion between the pathologist, the surgeon and the radiologist to reach the precise diagnosis.

Some of the limitations of this study was the retrospective nature of it. The small number of specimens was another limitation. Therefore, we recommend further studies with larger samples to fully assess the accuracy of FNAC for diagnosing salivary gland masses in Saudi Arabia.

\section{Conclusions}

FNAC is a reliable method with high specificity for malignant parotid gland tumors, and provides the surgeon with valuable information in preoperative diagnostics. FNAC is an easy to perform, inexpensive and cost-effective test with high overall accuracy in diagnosing benign and malignant salivary gland neoplasms. In our series, the overall sensitivity and specificity were $90.3 \%$ and $100 \%$, respectively. Thus, this method provides several advantages for both the clinicians and the patients.

\section{Additional Information}

\section{Disclosures}

Human subjects: Consent was obtained or waived by all participants in this study. King Abdullah International Medical Research Center issued approval SP20/123/J. Animal subjects: All authors have confirmed that this study did not involve animal subjects or tissue. Conflicts of interest: In compliance with the ICMJE uniform disclosure form, all authors declare the following: Payment/services info: All authors have declared that no financial support was received from any organization for the submitted work. Financial relationships: All authors have declared that they have no financial relationships at present or within the previous three years with any organizations that might have an interest in the submitted work. Other relationships: All authors have declared that there are no other relationships or activities that could appear to have influenced the submitted work.

\section{Acknowledgements}

We would like to thank the staff of Medical Records at King Abdulaziz Medical City, Jeddah, SA.

\section{References}

1. Ali NS, Akhtar S, Junaid M, Awan S, Aftab K : Diagnostic accuracy of fine needle aspiration cytology in parotid lesions. ISRN Surg. 2011, 2011:721525. 10.5402/2011/721525

2. Cole P, Pinkston JA: Incidence rates of salivary gland tumors: results from a population-based study . Otolaryngol Head Neck Surg. 1999, 120:834-840. 10.1016/S0194-5998(99)70323-2

3. Batsakis JG, Sneige N, El-Naggar AK: Fine-needle aspiration of salivary glands: its utility and tissue effects . Ann Otol Rhinol Laryngol. 1992, 101:185-188. 10.1177/000348949210100215

4. Layfield LJ, Glasgow BJ: Diagnosis of salivary gland tumors by fine-needle aspiration cytology: a review of clinical utility and pitfalls. Diagn Cytopathol. 1991, 7:267-272. 10.1002/dc.2840070311

5. Amedee RG, Dhurandhar NR: Fine-needle aspiration biopsy. Laryngoscope. 2001, 111:1551-1557. 10.1097/00005537-200109000-00011

6. Orell SR: Diagnostic difficulties in the interpretation of fine needle aspirates of salivary gland lesions: the problem revisited. Cytopathology. 1995, 6:285-300. 10.1111/j.1365-2303.1995.tb00574.x

7. Stanley MW: Selected problems in fine needle aspiration of head and neck masses . Modern Pathol. 2002, 15:342-350. 10.1038/modpathol.3880528

8. Gudmundsson JK, Ajan A, Abtahi J: The accuracy of fine-needle aspiration cytology for diagnosis of parotid gland masses: a clinicopathological study of 114 patients. J Appl Oral Sci. 2016, 24:561-567. 10.1590/1678775720160214

9. Zurrida S, Alasio L, Tradati N, Bartoli C, Chiesa F, Pilotti S: Fine-needle aspiration of parotid masses . Cancer. 1993, 72:2306-2311. 10.1002/1097-0142(19931015)72:8<2306::aid-cncr2820720804>3.0.c0;2-e

10. Rajwanshi A, Gupta K, Gupta N, Shukla R, Srinivasan R, Nijhawan R, Vasishta R: Fine-needle aspiration 


\section{Cureus}

cytology of salivary glands: diagnostic pitfalls--revisited. Diagnos Cytopathol. 2006, 34:580-584.

10.1002/dc. 20353

11. Elagoz S, Gulluoglu M, Yilmazbayhan D, Ozer H, Arslan I: The value of fine-needle aspiration cytology in salivary gland lesions, 1994-2004. ORL J Otorhinolaryngol Relat Spec. 2007, 69:51-56. 10.1159/000096717

12. İnançlı HM, Kanmaz MA, Ural A, Dilek GB: Fine needle aspiration biopsy: in the diagnosis of salivary gland neoplasms compared with histopathology. Indian J Otolaryngol Head Neck Surg. 2013, 65:121-125. 10.1007/s12070-012-0608-4

13. Aversa S, Ondolo C, Bollito E, Fadda G, Conticello S: Preoperative cytology in the management of parotid neoplasms. Am J Otolaryngol. 2006, 27:96-100. 10.1016/j.amjoto.2005.07.015 